\title{
ORGANIZAÇÕES E RESPOSTAS INSTITUCIONAIS A POLÍTICAS DE REFORMAS DO ESTADO: UM ESTUDO DE CASO NA ADMINISTRAÇÃO DIRETA DO EXECUTIVO FEDERAL BRASILEIRO ${ }^{1}$
}

\author{
Flávio da Cunha Rezende \\ Universidade Federal de Pernambuco
}

\begin{abstract}
RESUMO
Este artigo analisa padrões de respostas de organizações da administração direta do Poder Executivo Federal brasileiro a políticas de ajuste fiscal nos anos 90 . Baseada no argumento dos jogos repetidos de informação incompleta, a análise objetiva explicar porque, mesmo diante de políticas que visam a reduzir o tamanho e os gastos governamentais, os gastos com pessoal e o número de funcionários tendem a persistir no tempo.

PALAVRAS CHAVE: políticas públicas; reforma do Estado; burocracia, administração pública.
\end{abstract}

\section{INTRODUÇÃO}

Uma das principais questões temáticas para a Ciência Política contemporânea tem sido a de explicar porque tentativas de controlar os gastos e a expansão da burocracia pública têm se mostrado tarefa complexa e com resultados quase sempre aquém do esperado. Embora governos de todos os matizes tenham se engajado consideravelmente em formular e implementar políticas de reforma do Estado centradas em promover o controle dos gastos com o governo desde meados da década de 1980, como respostas à crise fiscal do setor público ${ }^{2}$, evidências empíricas confir-

1 Gostaria de agradecer a Humberto Falcão Martins e a Hiro Barros Kumasaka pelos incentivos para a produção deste artigo. Sou grato ainda aos pareceristas anônimos da Revista de Sociologia e Política pelos comentários, sugestões e recomendações à versão inicial.

$2 \mathrm{O}$ argumento de que as reformas administrativas, e as reformas do Estado mais amplamente, são políticas destinadas a lidar com a "crise fiscal do Estado" é um dos mais aceitos entre os mais variados analistas, e uma das principais interpretações e justificativas para tais políticas. Para o caso das novas democracias do Leste Europeu e da América Latina, como analisam Bresser Pereira, Maravall \& Przeworski (1993), a crise fiscal do Estado tem sido uma das principais motivações para a formulação e implementação de políticas de reforma administrativa. mam tal problema e, tanto nas economias avançadas como nos países em desenvolvimento, o governo continua a aumentar os seus gastos, sua dívida, e a expandir o seu tamanho. Fornecer uma explicação para tal problema e analisar empiricamente o caso da administração direta do governo federal brasileiro assume central relevância neste artigo.

Na literatura que analisa o problema do crescimento do governo, existem diversas explicações para tal fenômeno, e estas estão diretamente relacionadas à concepção do papel do Estado numa economia e sociedade orientada pelo mercado.

A primeira explicação relaciona a expansão dos gastos do governo ao seu papel de produção dos bens públicos e de controle de externalidades numa economia de mercado. A explicação é que dada a incapacidade de os mercados organizaremse eficientemente ${ }^{3}$ para produzir os bens públicos,

Este argumento tem balizado a política de reforma administrativa proposta e implementada no Brasil pelo Ministério da Administração Federal e Reforma do Estado desde 1995.

3 Na literatura de corte econômico essas situações em que o mercado não se organiza eficientemente são chamadas de falhas de mercado (market failures), as quais justificam a intervenção governamental numa sociedade 
os governos tendem a permanecer se expandindo.

A segunda explicação focaliza o argumento de que as funções de redistribuição de renda e riqueza do governo são o fator causal para o fenômeno. Ao se envolver no problema redistributivo entre grandes grupos, o governo é levado a expandir sua máquina burocrática e o seu nível de taxação sobre as rendas dos indivíduos. A terceira explicação centra sua atenção no papel dos grupos de interesse especiais como causa central para o crescimento do governo. Grupos de interesse organizam-se e agem no sentido de fazer que o governo expanda os seus gastos em programas governamentais que os beneficiem através de políticas públicas de corte distributivo. A quarta explicação é a de que o governo e sua burocracia têm uma natureza intrínseca de propensão à expansão dos gastos. O governo expande-se não apenas porque existe uma demanda permanente ou crescente por bens públicos, ou mesmo porque grupos de interesses especiais causam a expansão, mas sim porque os burocratas e a burocracia tendem a demandar mais recursos orçamentários do que o realmente necessário para realizar suas funções junto ao legislativo ${ }^{4}$. A quinta linha explicativa centra-se na idéia da "ilusão fiscal", a qual supõe que o governo cresce a partir de pequenas e imperceptíveis elevações dos impostos sobre os indivíduos. O mecanismo causal do crescimento do governo seria, portanto, a falsa percepção com que os indivíduos e grupos percebem a expansão do governo através do carga fiscal que sobre eles incidem. Embora a literatura apresente esse conjunto de explicações para o fenômeno da expansão do governo, poucos estudos se debruçam para analisar tal problema a partir de uma perspectiva que contemple o problema da reação, ou do comportamento estratégico das organizações do governo para manterem os recursos no tempo, como escolha racional.

Nesse sentido, o crescimento do governo está

orientada pelo mercado. $\mathrm{O}$ artigo seminal sobre as falhas de mercado é Bator (1958).

4 Esse argumento representa a clássica interpretação de Niskanen (1971), que, baseada no comportamento budget-maximizing dos burocratas, considera que, dado o problema de assimetria de informação entre o Executivo e o Legislativo, as diversas organizações do governo tendem a demandar mais orçamento do que o necessário, levando o governo a expandir os seus gastos. relacionado a um comportamento estratégico das organizações para garantir os seus recursos no tempo.

A explicação oferecida fundamenta-se na idéia de que, diante de políticas de controle dos gastos, as diversas organizações confrontam-se com estruturas de incentivos em que, do ponto de vista de uma organização individual, não seria racional promover reduções nos seus recursos, sem a garantia de que outras organizações façam o mesmo. A incerteza da cooperação seria o mecanismo causal da explicação. Sem a certeza de que os cortes afetam da mesma maneira o conjunto de organizações do governo, dado que fatores cruciais como a política, as relações de poder e a capacidade diferencial de barganha junto à estrutura decisória entram em jogo, as organizações preferem racionalmente optar por reduções mínimas em seus gastos e no número de funcionários. Com tal comportamento como racional, o governo tende a expandir ou manter os seus gastos e o seu tamanho no tempo. Este comportamento possibilita entender por que as políticas de reforma e de reforma administrativa são pouco atrativas e de difícil exequiibilidade, dado que políticas de downsizing 5 e redução dos gastos geram incentivos à não-cooperação.

A aplicação empírica se volta para a análise do comportamento de organizações da administração direta no Executivo federal brasileiro a partir dos anos 90, período em que o governo vem implementando políticas de controle dos gastos com pessoal e de redução do número de servidores federais nos mais diversos setores burocráticos e se engajando de modo decisivo na questão da reforma do Estado e da administração pública. Com base em dados quantitativos sobre despesas de pessoal e quantidade de servidores federais ${ }^{6}$ no

\footnotetext{
5 As políticas de downzising, ou de redução do número de funcionários públicos, como estratégia de reforma da administração pública, têm sido um dos componentes das reformas gerenciais no mundo desenvolvido e em desenvolvimento. Para uma compreensão das reformas no caso americano ver Rezende (1998); e para uma compreensão dos princípios das políticas de reforma do aparato burocrático federal no caso brasileiro e em perspectiva comparada, ver Bresser Pereira (1998).

6 O documento oficial utilizado para a sistematização dos dados empíricos que fundamenta a análise foi o $\mathrm{Bo}$ letim Estatístico de Pessoal produzido pelo Ministério da Administração Federal e Reforma do Estado no período fevereiro de 1996 a outubro de 1998.
} 
período fevereiro de 1996 a setembro de 1998, pretende-se analisar o comportamento e os padrões de respostas de setores da burocracia federal diante de políticas de controle e redução no tamanho e dos gastos governamentais.

O artigo está estruturado da seguinte forma. Na primeira seção, utilizando dados comparativos, são apresentadas evidências empíricas sobre o problema do crescimento do governo diante de políticas de controle dos gastos. Na parte seguinte, apresenta-se o modelo empírico utilizado no estudo de caso. Nas seções finais são analisados os dados empíricos para o caso brasileiro e extraídas as principais conclusões.

\section{A EXPANSÃO DO GOVERNO COMO FE- NÔMENO E COMO PROBLEMA}

\section{II.1. EVIDÊNCIAS INTERNACIONAIS}

Dados recentes da OECD (1998) mostram que: a) a dívida pública relativa ao produto interno bruto se elevou de 40,2\% em 1980 para 70,6\% em 1995 ; b) os gastos governamentais relativos ao produto interno bruto expandiram-se de 36,5\% em

Quadro 1. Comportamento do Setor Público em países desenvolvidos selecionados (1980-1995)

\begin{tabular}{|c|c|c|c|c|c|c|}
\cline { 2 - 7 } \multicolumn{1}{c|}{} & \multicolumn{2}{c|}{ Dívida pública/PIB } & \multicolumn{2}{c|}{ Gastos do governo/PIB } & \multicolumn{2}{c|}{$\begin{array}{c}\text { Emprego no setor } \\
\text { público/Total emprego (\%) }\end{array}$} \\
\cline { 2 - 7 } & $\mathbf{1 9 8 0}$ & $\mathbf{1 9 9 5}$ & $\mathbf{1 9 8 0}$ & $\mathbf{1 9 9 5}$ & $\mathbf{1 9 8 0}$ & $\mathbf{1 9 9 5}$ \\
\hline Total OECD & 40.2 & 70.6 & 36.5 & 40.3 & n.d & n.d \\
\hline Estados Unidos & 37.0 & 63.4 & 31.4 & 33.2 & 16.4 & 15.5 \\
\hline Inglaterra & 54.0 & 60.0 & 43.0 & 43.2 & 21.2 & 14.3 \\
\hline França & 30.9 & 60.7 & 46.1 & 53.9 & 20.2 & 24.7 \\
\hline Canadá & 44.0 & 100.5 & 38.8 & 46.5 & 19.5 & 20.7 \\
\hline Austrália & n.d & 43.4 & 31.4 & 36.3 & 16.3 & 15.2 \\
\hline
\end{tabular}

Fonte: OECD (1998).

1980 para 40,3\%; e c) o emprego no setor público elevou-se ou manteve-se constante ${ }^{7}$. O quadro a seguir ilustra o comportamento destas três variáveis para diversos países selecionados ${ }^{8}$.

Nos países em desenvolvimento, dados oficiais revelam que os governos continuaram a expandir suas dívidas, os gastos e o tamanho do aparato

\footnotetext{
7 Estatísticas da OECD para o período 1960-1985 revelam que os gastos governamentais proporcionais ao produto interno bruto se elevaram de 26,6 \% em 1960 para 42,9 $\%$ em 1985, revelando uma forte expansão do setor público nas economias consideradas desenvolvidas. Desnecessário dizer que o mesmo fenômeno verifica-se nos países em desenvolvimento, e especialmente na América Latina, onde o padrão e o estilo de desenvolvimento foi centrado no Estado.

8 Rezende (1996), analisando o perfil dos gastos públicos no período 1980-1992 para Estados nacionais em países desenvolvidos e em desenvolvimento, revela a existência de uma profunda diferenciação nas transformações ocorridas no papel do Estado na década. Os países em desenvolvimento transformam significativamente seus papéis na direção do "Estado mínimo", enquanto os países desenvolvidos pouco transformam seus papéis e apresentam perfis alocativos que pouco tem a ver com o Estado mí-
} nimo. governamental a partir dos anos 80, apesar de consideráveis esforços para controlar a expansão e o gasto governamental. O quadro abaixo apresenta como se deu a evolução da dívida pública proporcional ao produto interno bruto para alguns países em desenvolvimento no período 19801995.

Quadro 2. Dívida pública/PIB - países em desenvolvimento selecionados (1980-1995)

\begin{tabular}{|c|c|c|}
\cline { 2 - 3 } \multicolumn{1}{c|}{} & \multicolumn{2}{c|}{ Dívida Pública/PIB (\%) } \\
\cline { 2 - 3 } \multicolumn{1}{c|}{} & 1980 & 1995 \\
\hline Brasil & 31,2 & 24 \\
\hline Chile & 45,5 & 43,3 \\
\hline Índia & 11,9 & 28,2 \\
\hline Quênia & 48,1 & 97,7 \\
\hline Turquia & 27,4 & 44,1 \\
\hline Uruguai & 17 & 32,4 \\
\hline Venezuela & 42,1 & 49 \\
\hline Argentina & 35,7 & 43,4 \\
\hline México & 42,3 & 60,7 \\
\hline
\end{tabular}

Fonte: WORLD BANK; elaboração do autor. 
Para o conjunto de países da América Latina tal fenômeno não se constitui exceção, e os dados disponíveis (IBD, 1997) revelam que tendem a expandir consideravelmente sua dívida proporcional ao produto interno bruto.

Os dados apresentados ilustram o problema de crescimento do governo e de sua dívida mesmo diante de políticas de ajuste fiscal que preconizam a redução dos gastos governamentais e controle fiscal do setor público. Na seção seguinte, ilustraremos tal problema para o Estado brasileiro no período pós-Nova República.

\section{II.2. EVIDÊNCIAS SOBRE A EXPANSÃO DOS GASTOS GOVERNAMENTAIS COM PESSOAL E DO TAMANHO DO GOVERNO PARA O CASO BRASI- LEIRO A PARTIR DA NOVA REPÚ- BLICA}

Apesar dos esforços substanciais do governo em reduzir as despesas governamentais com a administração pública, dados oficiais revelam o crescimento das despesas de pessoal e do número de servidores federais no período 1987-1997 na administração pública brasileira. As políticas de controle e redução da expansão dos gastos com o governo e seu aparato burocrático ocorreram em duas fases distintas: a) o período anterior a 1995, quando ocorreu um processo de reformas administrativas com objetivos de reduzir os gastos governamentais na esfera federal; b) o período a partir de 1995, quando começaram os esforços governamentais a controlar os gastos de pessoal no Executivo federal, dando início à chamada Reforma do Estado, desencadeada pelo MARE.

Em primeiro lugar, como apresentado no gráfico 1, observa-se o comportamento da variável despesas de pessoal no período. O que se ressalta é que as despesas com servidores mais do que duplica no período, saltando de $\mathrm{R} \$ 19,4$ bilhões no ano de 1987 para $\mathrm{R} \$ 44,2$ bilhões dez anos depois.

Gráfico 1. Despesas de pessoal da União (1987-1997)

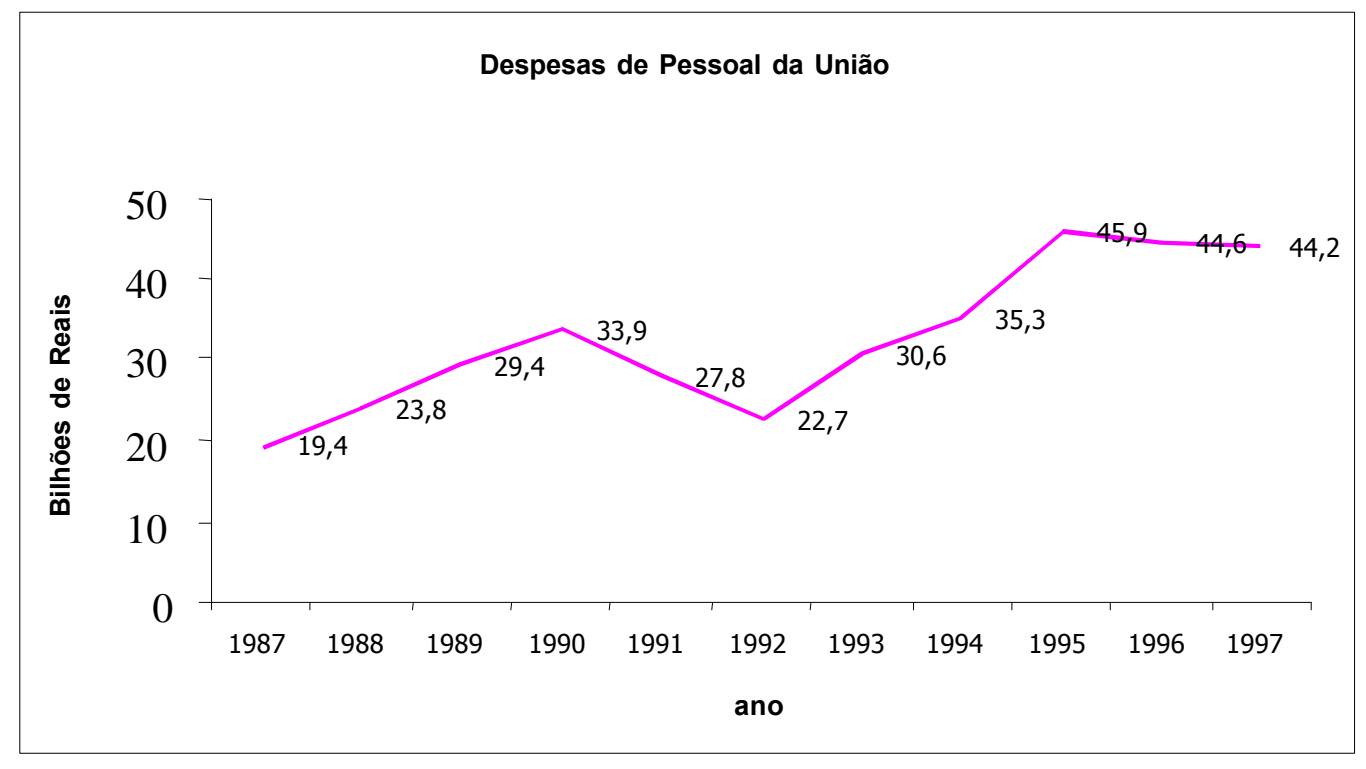

Quando analisada a evolução da variável quantidade de servidores federais no mesmo período, o que se observa, como apresentado no gráfico 2, é que o governo federal realizou consideráveis cortes no número de funcionários, mostrando que as reformas do Estado vêm conseguindo reduzir o número de servidores ativos. Mesmo reduzindo o número de funcionários, as despesas de pessoal continuam a se elevar. 
Gráfico 2. Número de Servidores Ativos

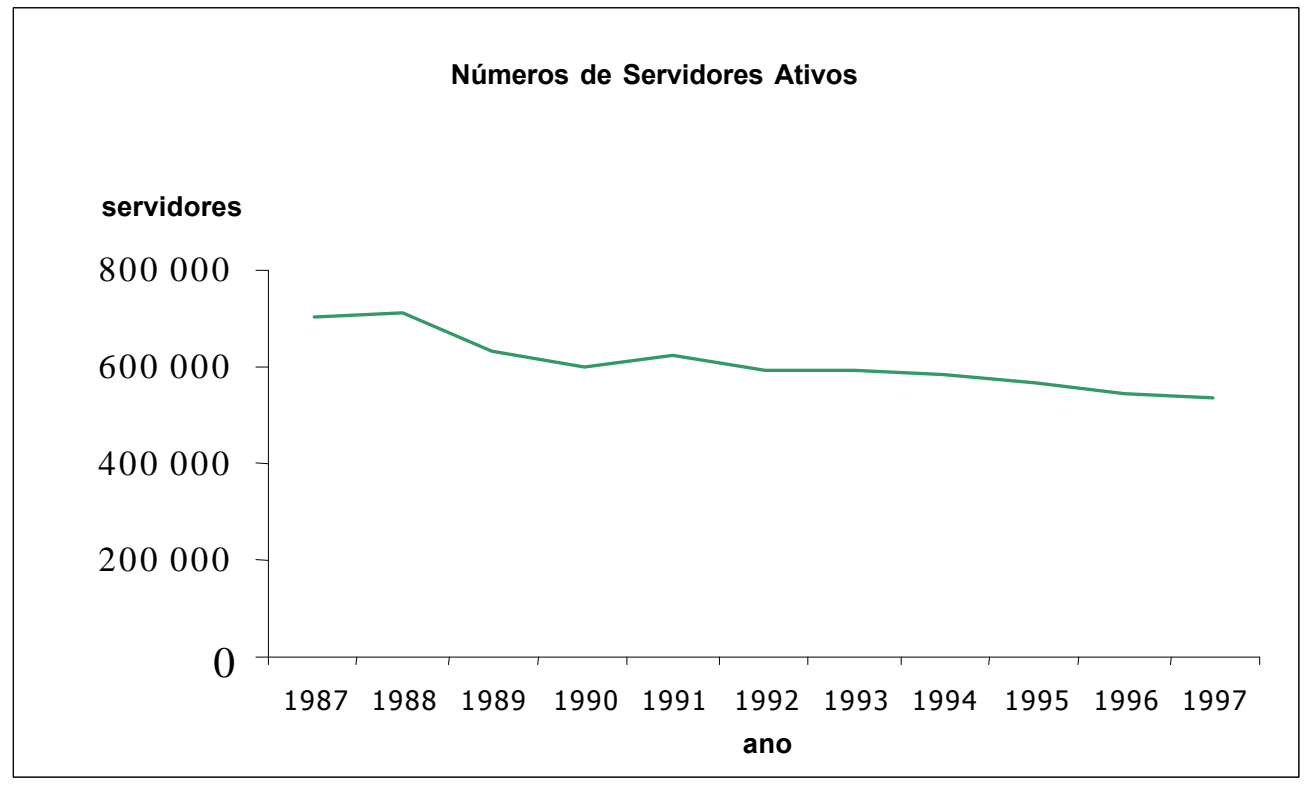

O gráfico a seguir mostra que os comportamentos das despesas de pessoal, tanto para ativos quanto para aposentados, apresentam curvas similares, sendo as despesas de ativos sempre superiores às de aposentados, assim como as duas curvas têm os mesmos pontos de inflexão. As curvas revelam: a) elevação das despesas no período $1987-$
1990; b) contração no período 1990-1992; c) expansão no período 1993-1995; e, finalmente: d) estabilidade (ou pequenas reduções) no período a partir de 1995. Isso mostra que as despesas de pessoal tendem a se expandir, e que apenas em momentos eventuais - o período Collor - conseguiuse reduzir de maneira drástica tais despesas.

Gráfico 3. Despesas de pessoal de União - ativos e aposentados

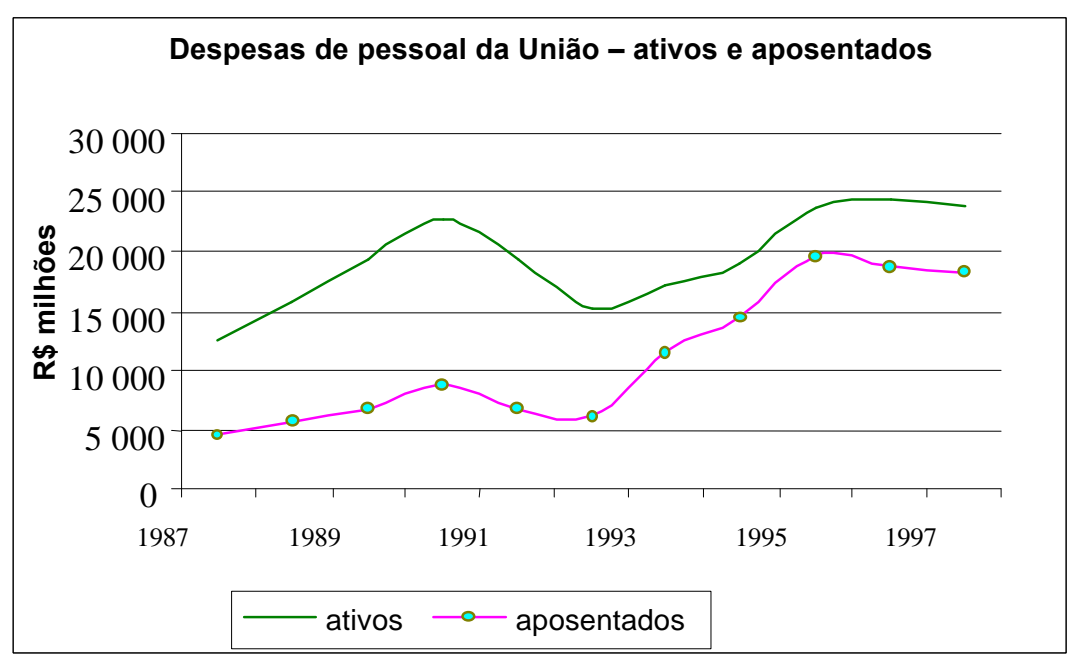

No entanto, vale salientar que os cortes governamentais não ocorrem de maneira homogênea para os diversos segmentos da administração federal, dependendo em muito da natureza do Estado em ação. Os dados apresentados no gráfico 4 revelam que existe uma forte diferenciação quando se comparam os três poderes. As despesas do Executivo e do Legislativo mantiveram-se praticamente no mesmo patamar de 1987, as despesas do Judiciário aumentaram aproximadamente em sete vezes, revelando que os diferentes Poderes comportamse diferentemente frente a políticas de controle dos 
gastos e de ajuste fiscal. Haveria, portanto, setores que tendem a aumentar suas despesas mesmo dian- te das claras intenções do governo em implementar políticas de controle e redução dos gastos.

Gráfico 4. Evolução das despesas de pessoal nos três Poderes do governo (1987=100)

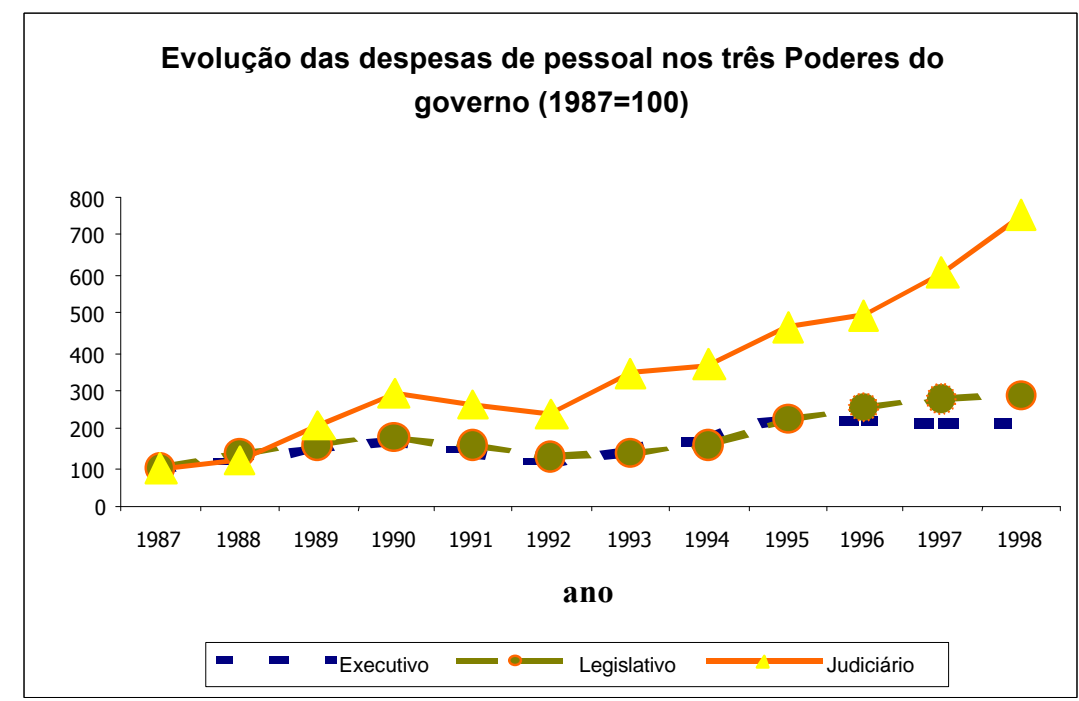

Quando considerado em valor absoluto, a evolução das despesas de pessoal para o poder Executivo, os dados revelam que estas aumentaram consideravelmente no período, e a curva apresenta o mesmo formato que a curva mais agregada das despesas de pessoal - mostrando o que esta variável pesa no comportamento geral das despesas do governo federal, isto é, em proporção. Se essas representavam $86,8 \%$ das despesas em 1987 , passaram a ser $80,2 \%$ no final da série. Isso significa que os dois outros Poderes passaram a apresentar maior participação relativa nas despesas de pessoal, sobretudo com a explosão dos gastos no Judiciário.

Quando analisados os dados das despesas de pessoal dos poderes Legislativo e Judiciário, como apresentado no gráfico 5, eles mostram que, enquanto o Judiciário apresentou uma quase exponencial elevação dos seus gastos com pessoal, o Legislativo comportou-se de modo estável.

Gráfico 5. Despesas de Pessoal - Legislativo e Judiciário

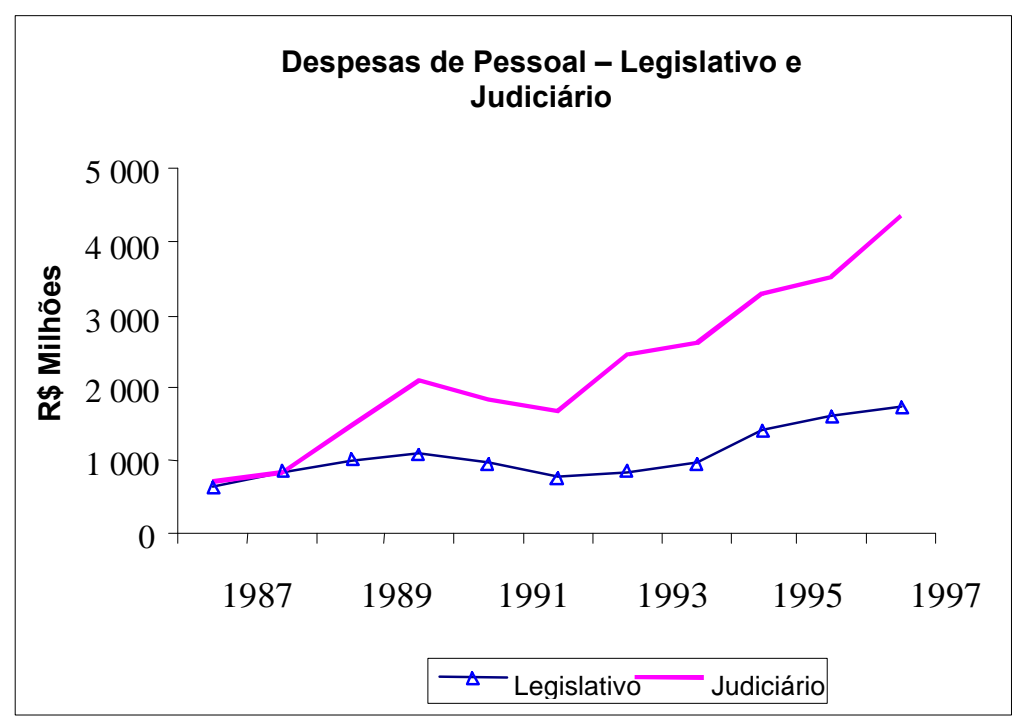


Os dados apresentados mostram fundamentalmente o crescimento das despesas com pessoal e o número de servidores mesmo diante de políticas de controle e redução dos gastos do governo.

\section{AS POLÍTICAS DE REFORMA DO ES- TADO}

\section{III.1. AS POLÍTICAS DE CONTROLE E AJUSTE DOS GASTOS DO GOVERNO}

As políticas de reforma do Estado, sobretudo em sua dimensão relativa à redução do tamanho do Estado e transformação do seu papel, têm se constituído em uma das principais políticas públicas na agenda governamental desde os anos $80^{9}$. A experiência internacional revela que, a partir de meados dos anos 80 , um amplo conjunto de países vem se engajando na promoção de políticas de reforma do Estado, as quais têm como ponto comum os objetivos de controle com os gastos e tamanho do Estado, entendidos como controle do número de funcionários públicos, melhoria da performance das instituições públicas e transformação do papel do Estado ${ }^{10}$. Em economias avançadas tais como os EUA, Inglaterra, Nova Zelândia, Austrália, e mais recentemente no

9 Na literatura brasileira, a discussão em torno da reforma do Estado, e sobretudo da reforma administrativa, tem como locus institucional o extinto MARE e a ENAP (Escola Nacional de Administração Pública). A Revista do Serviço Público da ENAP; os Cadernos MARE da Reforma do Estado, e a Revista Reforma Gerencial têm sido as principais produções especializadas na questão da reforma. Spink \& Bresser Pereira (1998) contém uma coletânea de artigos de autores nacionais e internacionais sobre a reforma. Melo (1999) organizou recentemente uma produção de artigos sobre a reforma do Estado e a questão da mudança institucional no Brasil. Para uma discussão das reformas no setor público e estudos de caso na Europa, ver Lane (1997).

10 Certamente a reforma do Estado engloba dimensões mais amplas e outros objetivos (qualidade na intervenção governamental, melhoria dos processos de gestão, capacitação profissional dos servidores, mudanças tecnológicas, inovações institucionais, redesenho de incentivos, orientação para resultados e missões etc.) do que as consideradas aqui. $\mathrm{O}$ interesse aqui, deliberadamente reducionista, é o de entender que organizações do governo cooperam ou não com os objetivos, digamos primários e mais "duros" da reforma, sobre os quais se pode trabalhar com maior facilidade de mensuração, e que ainda têm sido a parte mais difícil de executar nas políticas das reformas do Estado, na experiência nacional e internacional.
Brasil, as administrações vêm tentando dramaticamente promover tais objetivos ${ }^{11}$. $\mathrm{O}$ argumento central para explicar a existência e a necessidade das reformas parte da idéia de que a redução e o controle dos gastos públicos promoveria o equilíbrio orçamentário e reduziria problemas de crise fiscal, por um lado; por outro lado, que a redefinição do papel do Estado, em termos de redesenho de suas instituições e mudança nas suas funções, tenderia a fazer com que este passasse a desempenhar funções com maior performance, accountability e efetividade.

Neste trabalho, as políticas de reformas serão entendidas a partir de duas variáveis: redução das despesas de pessoal, e redução do número de funcionários, nas diversas organizações do governo. O problema a ser analisado é se, quando o governo federal implementa tais políticas, como uma dada organização no interior da burocracia coopera ou não coopera com tal política. Nesse sentido, a análise parte das seguintes premissas. Para o governo, por um lado, o objetivo é o de conseguir atingir a máxima redução dos gastos com o governo num dado período de tempo; para cada uma das organizações do governo, por outro lado, o problema é o de como reduzir tais "recursos" de maneira tal que seja possível garantir um nível de recursos para sua sobrevivência. A escolha para uma organização individual seria a de cooperar ou de nãocooperar, mas, também, a de quanto cooperar. Nesse sentido, vale pensar que as reformas podem ser entendidas como um jogo repetido de informação incompleta entre vários jogadores, ou mesmo como um problema principal-agente, entre o governo e as diversas organizações. Diante dessa particular estrutura de incentivos, o governo tentará implementar as reformas fazendo com que as diversas organilzações do governo se engajem na promoção desses interesses, e as organizações tentarão resistir, ou cooperar num grau que não afete sua sobrevivência no tempo.

Caso tais políticas ocorressem num contexto em que o governo central tivesse completa capa-

\footnotetext{
11 Para uma ampla compreensão dos princípios, propostas, principais issues nas políticas de redefinição do papel do Estado nas reformas orientadas pelo Mercado, e, ainda as principais lições aprendidas por instituições multilaterais nas políticas de reforma do Estado nos países em desenvolvimento, sobretudo na experiência asiática, ver Stiglitz (1998).
} 
cidade de enforcement e máximo poder de autoridade sobre os diversos setores burocráticos para implementar as reformas livre de restrições, seria de se esperar que as diversas organizações se engajassem, ou cooperassem com os objetivos desejados pelo governo, qual seja, o de reduzir o número de funcionários e as despesas com pessoal num curto espaço de tempo. Na realidade, como a implementação dessas políticas ocorrem em ambientes bastante diferentes desse "ideal", é plausível supor que as organizações tendam a apresentar respostas cooperativas e não-cooperativas, de modo estratégico, que permitem entender a forma pelo qual o governo tende a continuar a se expandir.

\section{III.2. O COMPORTAMENTO ESTRATÉGICO DE UMA ORGANIZAÇÃO DO GOVER- NO DIANTE DAS REFORMAS}

Diante de uma política $P$ que tem por objetivo reduzir o número de funcionários públicos e as despesas de pessoal (ou mais amplamente, reduzir os recursos críticos disponíveis para o funcionamento das organizações do governo) num intervalo de tempo $t$, uma organização $O$ poderia comportar-se $^{12}$ : a) cooperativamente, reduzindo tanto o seu número de funcionários, quanto as despesas com pessoal; b) não-cooperativamente, tendo o comportamento oposto; c) incrementalmente, com pequenos intervalos de respostas cooperativas, e não-cooperativas.

O modo específico pelo qual uma organização responde num dado intervalo de tempo representa o conjunto de esforços que uma organização faz para atender aos interesses do governo. Para uma organização qualquer, e para toda a burocracia, por extensão, cada uma dessas respostas está associada a uma distribuição de custos e benefícios - os pay-offs - resultantes de cada escolha. A premissa central da análise do comportamento individual de uma organização aqui adotada é a de que esta prefere responder de modo a garantir

\footnotetext{
12 As repostas dos setores burocráticos são aqui entendidas como manifestações concretas do modo como se relacionam no caso brasileiro questões tais como poder, poder político, e fundamentalmente, o modo particular como a política interfere com a administração numa dada estrutura burocrática. Assim, a análise das respostas, ou do padrão de respostas, permite, por aproximação, mensurar empiricamente a relação entre política, administração e políticas públicas.
}

um nível constante de recursos que garantam sua sobrevivência no tempo; nesse sentido, uma organização não apresenta uma estrita preferência por não-cooperar, mas, sim, uma preferência estratégica em reduzir recursos até um ponto em que esses cortes não venham a comprometer a sobrevivência da organização dentro da estrutura burocrática. Outro ponto fundamental para entender o comportamento de uma organização seria o de considerar que estas irão se comportar de modo cooperativo na medida em que estas tiverem mais "certeza" de que outras organizações estariam cooperando com os objetivos do governo no tempo.

Ao assumir tais premissas para explicar o comportamento burocrático diante das reformas, o que se pretende mostrar é que cada organização possui um "nível limite de cooperação", ou nível de tolerância para com as reformas, a partir do qual ela deixa de apresentar qualquer interesse em cooperar. A cooperação além desse ponto-limite colocaria em risco a sua sobrevivência, e, portanto, representaria uma escolha sub-ótima para a organização. Neste sentido, pode-se partir da premissa que uma organização do governo comporta-se de modo não-cooperativo a partir do momento em que a diminuição dos recursos críticos para a organização ultrapassa esse limite. Como apresentado na figura abaixo, que representa o interesse de uma organização individual em cooperar com a reforma no tempo, a premissa é de que o interesse em cooperar, atinge um ponto de máximo no tempo, a partir do qual não é atrativo cooperar dado o risco que essa cooperação apresenta para a sobrevivência da organização.

$\mathrm{O}$ interesse de uma organização $O$ seria o de

Figura 1. Interesse em cooperar com as políticas de reforma Interesse em cooperar com a reforma

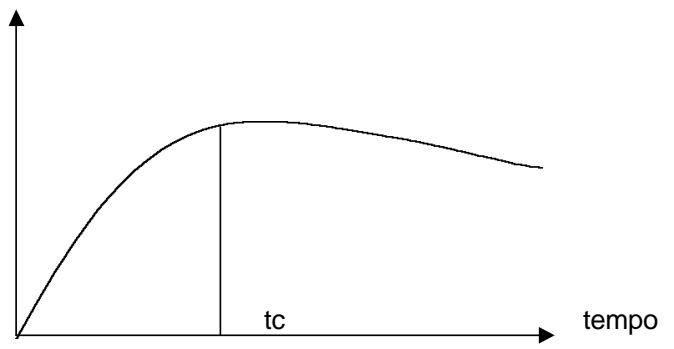

agir de modo a garantir sua sobrevivência no tempo, e por tal razão, ela necessita manter um certo nível de recursos (no caso particular, se a 
redução do número de funcionários ou das despesas de pessoal chegar a zero, numa situação hipotética essa organização deixaria de existir) que garanta sua existência no interior da burocracia. A organização portanto irá comportar-se de modo a evitar que o governo reduza esses recursos a uma quantidade indesejada pela organização. Para tal, ela irá mobilizar recursos (materiais e nãomateriais) para conseguir os recursos necessários no processo político. Os incentivos para cooperar com as reformas são positivos até o ponto em que os cortes pretendidos pelo governo superam um patamar suportável de cortes, acima do qual as organizações têm pequenos incentivos para continuar cooperando com as reformas pretendidas. Diante desses incentivos, é de se esperar que individualmente, e por extensão, coletivamente, as organizações respondam estrategicamente cooperando e não-cooperando com os objetivos do governo, de modo incremental ${ }^{13}$.

\section{III.3. O COMPORTAMENTO ESTRATÉGICO DIANTE DAS REFORMAS COMO UM JOGO REPETIDO DE INFORMAÇÃO INCOMPLETA}

Por outro lado, considerando duas organizações $A$ e $B$, considera-se que o comportamento da organização $A$ diante das reformas está relacionado à resposta de $B$, e vice-versa. Diante de uma situação de informação incompleta que $A$ tem sobre $B$ no que se refere ao seu nível de cooperação com a reforma, como é de se supor que na realidade ocorra, resulta um problema "coletivo" de cooperação: uma organização $A$ teria reduzidos incentivos a cooperar com a reforma quanto maior for a assimetria de informação entre $A$ e $B$. Uma vez que $A$ não tem informação completa de que $B$ opta pela cooperação, e coopera na mesma intensidade que $A, A$, ao cooperar, pode estar "arcando com os custos associados à diminuição dos recursos críticos", enquanto a outra organização $B$ (ou outras) poderia estar ganhando com a

\footnotetext{
13 No mundo real, diferentes organizações, dadas suas diferentes habilidades e acesso a recursos políticos e suas posições na estrutura burocrática, apresentam diferentes capacidades para resistir aos cortes pretendidos pelo governo. Com isso, explicar-se-ia porque no mundo real diferentes organizações apresentam maior cooperação ou não-cooperação do que outras num mesmo governo. A aplicação empírica e a análise que dela resulta irá mostrar o comportamento diferencial das diversas organizações na burocracia federal brasileira.
}

cooperação de $A$. Isso faz que $A$ prefira o comportamento caroneiro (free-rider) previsto por Olson (1965) na Lógica da Ação Coletiva. Com efeito, diante de uma situação de informação incompleta e de assimetria de informação, como $A$ não tem a garantia de que $B$ esteja sendo atingida pela redução de recursos na mesma intensidade que $A$, esta tem pequenos incentivos a cooperar, e grandes incentivos a se comportar de modo nãocooperativo.

Diante desses incentivos, torna-se difícil para uma agência $A$ cooperar, uma vez que outras agências podem estar se comportando oportunisticamente diante da reforma, evitando maiores reduções dos recursos disponíveis para si, no tempo, enquanto $A$ arca com os custos associados à reforma. Nesse sentido, as políticas de reforma tendem a gerar pequenos incentivos para uma organização a diminuir a quantidade de recursos críticos no tempo, sendo baixa portanto a probabilidade de um "engajamento espontâneo" das agências governamentais com os interesses do governo ${ }^{14}$.

\section{MODELANDO OS PADRÕES DE RES- POSTAS DAS AGÊNCIAS DO GOVER- $\mathrm{NO}$}

No sentido de mensurar empiricamente os padrões de respostas a políticas de reforma do Estado, foram considerados alguns indicadores para mensurar a cooperação e a não-cooperação num dado intervalo de tempo $t$. Em primeiro lugar, consideram-se séries temporais (mensais) para cada uma das variáveis de interesses - quantidade de servidores e despesas de pessoal - e calcula-se a variação absoluta mensal para cada organização $O$, sendo esta calculada a partir da expressão $\mathrm{D}=$ $\mathrm{A}(\mathrm{j})-\mathrm{A}(\mathrm{j}+1)$, onde $A$ é a variável de interesse, e $j$ um dado mês. $O$ valor de $D$ pode ser nulo, positivo ou negativo. Em caso positivo, significa que a organização elevou o valor da variável de interesse, $\mathrm{e}$, nesse sentido não cooperou com os objetivos gerais do governo. Quando o valor de $A$ é negativo, significa que a organização cooperou com o governo neste intervalo de tempo; e, quanto nulo, ela nem cooperou, nem não-cooperou.

Para o intervalo de tempo $t$, considerando o total dos intervalos de tempo $j$, parte-se para

14 Um tratamento formal tendo com base a teoria dos jogos vem sendo por mim realizado no artigo Rezende (1999). 
mensurar as seguintes variáveis para cada uma das organizações:

a) Cooperação (C): calculado como sendo o somatório de todas as respostas negativas $(\Delta<0)$, significando o total acumulado dos esforços da organização no sentido de reduzir o número de servidores, e/ou as despesas de pessoal, no intervalo de tempo $t$. Cooperação significa o quanto uma organização respondeu de modo cooperativo às políticas do governo;

b) Não-cooperação (NC): calculado como sendo o somatório de todas as respostas positivas $(\Delta>0)$, significando o total acumulado dos esforços da organização no sentido de elevar o número de servidores, e/ou as despesas de pessoal, no intervalo de tempo $t$. Não-cooperação significa o quanto uma organização respondeu às políticas do governo de modo não-cooperativo;

c) Cooperação/Não-cooperação (C/NC): calculado como sendo o quociente em valor absoluto entre a Cooperação e a Não-cooperação ao final do intervalo de tempo $t$. Este quociente representa o trade-off entre respostas cooperativas e não-cooperativas que uma organização realiza num determinado período de tempo. No caso de este índice ser nulo, significa que a organização não coopera de modo algum com o governo. Em caso de estar entre 0 e 1 , significa que ela coopera, mas em menor intensidade do que não-coopera; e em caso de ser maior do que 1 , significa que ela coopera muito mais intensamente do que não coopera.

d) Resposta líquida (RL): corresponde à soma entre as respostas cooperativas e nãocooperativas. Em caso de RL ser positivo significa que a não-cooperação foi maior do que a cooperação; e em caso negativo, a nãocooperação foi superior à cooperação no intervalo de tempo $t$. e) Número de respostas cooperativas (FC): calculado como sendo o número de respostas cooperativas que uma dada organização exibe no intervalo de tempo $t$. Isso significa em quantos intervalos de tempo a organização coopera com o governo.

f) Número de respostas não-cooperativas (FNC): calculado como sendo o número de respostas não-cooperativas que uma dada organização exibe no intervalo de tempo $t$. Isso significa em quantos intervalos de tempo a organização não-coopera com o governo.

g) Grau de cooperação/Não-cooperação (K): calculado com sendo o quociente entre o número de respostas cooperativas e não-cooperativas. Este indicador significa o grau em que a organização procura cooperar com o governo, e o número de vezes que exibe o comportamento contrário. Na seção seguinte, analisam-se os dados e resultados para organizações da Administração Federal direta brasileira.

\section{ANÁLISE EMPÍRICA PARA O CASO BRASILEIRO}

\section{V.1.RESPOSTAS INDIVIDUAIS - NÚMERO DE SERVIDORES}

Quando analisados os esforços de cooperação e de não-cooperação das diversas organizações do governo quanto à variável número de servidores, os dados revelam que: a) todas as organizações apresentam algum grau de cooperação e de não cooperação. Isso fundamentalmente significa que não existe um comportamento monolítico de cooperar apenas, ou de não-cooperar; b) existem organizações que cooperam muito mais do que não cooperam, e outras que apresentam o comportamento contrário. Quando considerado em seu total, os dados revelam que o governo coopera mais do que não-coopera, uma vez que C (-87 776) >> NC (40 257).

Quadro 1. Cooperação e Não-cooperação por organização do governo

\begin{tabular}{lcc}
\hline Organização do Executivo & Cooperação (C) & Não-Cooperação (NC) \\
\hline Presidência da República & -9055 & 8052 \\
EMFA & -182 & 810 \\
AGU & -55 & 601 \\
Ex-Ministérios & -3205 & 3067 \\
Ex-Territórios & -5468 & 1366
\end{tabular}




\begin{tabular}{lcc} 
MARE & -1116 & 1180 \\
Aeronáutica & -1452 & 325 \\
Agricultura & -9439 & 1301 \\
Assuntos Fundiários & -255 & 6305 \\
Ciência e Tecnologia & -838 & 363 \\
Comunicações & -342 & 332 \\
Cultura & -859 & 397 \\
Educação & -20128 & 13857 \\
Esportes & -28 & 28 \\
Exército & -1946 & 114 \\
Fazenda & -3327 & 3265 \\
Indústria e Comércio & -431 & 385 \\
Justiça & -2171 & 1436 \\
Meio-Ambiente & -3316 & 2472 \\
Minas e Energia & -603 & 305 \\
Planejamento & -3040 & 2321 \\
Previdência & -6696 & 374 \\
Relações Exteriores & -599 & 1116 \\
Saúde & -18440 & 811 \\
Trabalho & -3382 & 2604 \\
Transporte & -4263 & 2388 \\
\hline Total & $\mathbf{- 8 7 7 4 6}$ & $\mathbf{4 0 2 5 7}$ \\
\hline
\end{tabular}

No sentido de analisar melhor os esforços cooperativos em relação aos não-cooperativos no nível de cada organização, apresentaremos a relação $\mathrm{C} / \mathrm{NC}$ esquematicamente dividida em três intervalos: a) de 0 a 1 , indicando que a cooperação é menor ou igual à não-cooperação; b) entre 1 e 5, quando a cooperação é bem maior que a nãocooperação; e c) maior do que 5 , indicando aquelas agências que tendem a cooperar muito com o governo.

O conjunto de organizações que apresentam $\mathrm{C} / \mathrm{NC}$ entre 0 e 1 são apenas 6 , sendo estas, conforme pode-se visualizar no quadro abaixo, divididas em organizações que cooperam pouquíssimo Assuntos Fundiários, AGU e EMFA -, e outras que tendem a apresentar maior cooperação MARE, Relações Exteriores e Esportes.

Quadro 2. C/NC entre 0 e 1

\begin{tabular}{ll}
\hline Assuntos Fundiários & 0,04 \\
AGU & 0,09 \\
EMFA & 0,22 \\
Relações Exteriores & 0,54 \\
MARE & 0,95 \\
Esportes & 1,00 \\
\hline
\end{tabular}

O outro conjunto de organizações, no intervalo de $\mathrm{C} / \mathrm{NC}$ entre 1 e 5 , revela que um número maior de organizações - 16 - engaja-se com maior intensidade na cooperação com o governo. O quadro abaixo revela a profunda diferenciação na forma com que as organizações cooperam com o gover- no, indo de situações em que os esforços cooperativos são pouco superiores aos não-cooperativos, como é o caso da Fazenda e de Comunicações, para situações em que estes atingem valores quase quatro vezes superiores, como é o caso do ExTerritórios e da Aeronáutica.

\begin{tabular}{cc} 
Quadro 3. C/NC entre 1 e 5 & \\
\hline Fazenda & 1,02 \\
Comunicações & 1,03 \\
Ex-Ministérios & 1,04 \\
Presidência da República & 1,12 \\
Indústria e Comércio & 1,12 \\
Trabalho & 1,30 \\
Planejamento & 1,31 \\
Meio-Ambiente & 1,34 \\
Justiça & 1,51 \\
Educação & 1,45 \\
Transporte & 1,79 \\
Minas e Energia & 1,98 \\
Cultura & 2,16 \\
Ciência e Tecnologia & 2,31 \\
Ex-Territórios & 4,00 \\
Aeronáutica & 4,47 \\
\hline
\end{tabular}

Já no conjunto de organizações que apresentam cooperação maior que a não-cooperação maior que cinco vezes há apenas 4 , sendo que o setor Saúde é aquele no qual os esforços de cooperação são de intensidade 22 vezes maior que a não-cooperação.

Quadro 4. $C / N C>5$

\begin{tabular}{ll}
\hline Agricultura & 7,26 \\
Exército & 17,07 \\
Previdência & 17,90 \\
Saúde & 22,74 \\
\hline
\end{tabular}


Em relação ao número de respostas cooperativas e não-cooperativas no período, os dados revelam que apenas duas organizações - AGU e Indústria e Comércio - apresentam um número de respostas cooperativas inferior às não-cooperativas, indicando que na maior parte do tempo as organizações engajam-se - embora de maneira bastante diferenciada - em respostas cooperativas, ao menos na variável número de servidores. Apenas 4 organizações apresentam um número de respostas cooperativas que é cinco ou mais vezes superior ao número de respostas não-cooperativas.

Quadro 5 - Número de Respostas cooperativas e Não-cooperativas por organização

\begin{tabular}{lccc}
\hline Organização & freqüência C & freqüência NC & FC/FNC \\
\hline AGU & 5 & 17 & 0,29 \\
Indústria e Comércio & 11 & 12 & 0,92 \\
Presidência da República & 12 & 11 & 1,09 \\
EMFA & 12 & 11 & 1,09 \\
Esportes & 10 & 8 & 1,25 \\
Comunicações & 13 & 10 & 1,30 \\
Fazenda & 14 & 9 & 1,56 \\
Justiça & 15 & 8 & 1,88 \\
MARE & 15 & 8 & 1,88 \\
Ciência e Tecnologia & 16 & 7 & 2,29 \\
Educação & 17 & 6 & 2,83 \\
Agricultura & 19 & 4 & 4,75 \\
Cultura & 19 & 4 & 4,75 \\
Ex-Ministérios & 10 & 2 & 5,00 \\
Aeronáutica & 20 & 3 & 6,67 \\
Assuntos Fundiários & 10 & 1 & 10,00 \\
Ex-Territórios & 21 & 2 & 10,50 \\
\hline
\end{tabular}

\section{V.2. RESPOSTAS INDIVIDUAIS - DESPE- SAS DE PESSOAL}

Quando analisados os esforços de cooperação e de não-cooperação das diversas organizações do governo em relação à variável despesas de pessoal, conforme apresentado no quadro abaixo, os dados também revelam que: a) todas as organizações apresentam algum grau de cooperação e de nãocooperação. Isso fundamentalmente significa que não existe um comportamento monolítico de cooperar apenas, ou de não-cooperar; b) a grande maioria das organizações tende a exibir um comportamento não-cooperativo, sendo apenas a Presidência da República e o Ministério da Agricultura aquelas organizações que cooperam com os objetivos do governo.

Nesse sentido, os dados revelam que as organizações comportam-se diferentemente diante das despesas de pessoal que diante do número de servidores. As organizações conseguem cooperar cortando funcionários, mas não reduzindo as despesas.

Quadro 6 - Cooperação e não-cooperação por organização do governo

\begin{tabular}{lcc}
\hline Organização & Cooperação (C) & Não-Cooperação (NC) \\
Presidência da República & -29484 & 29248 \\
EMFA & -3205 & 3495 \\
AGU & -2304 & 2723 \\
Ex-Ministérios & -3777 & 3777
\end{tabular}




\begin{tabular}{|c|c|c|}
\hline Ex-Territórios & -101780 & 107357 \\
\hline MARE & -4687 & 5539 \\
\hline Aeronáutica & -51211 & 56305 \\
\hline Agricultura & -110818 & 99010 \\
\hline Assuntos Fundiários & -18871 & 39826 \\
\hline Ciência e Tecnologia & -48591 & 52517 \\
\hline Comunicações & -72282 & 73783 \\
\hline Cultura & -10563 & 11003 \\
\hline Educação & -625030 & 688399 \\
\hline Esportes & -488 & 491 \\
\hline Exército & -59262 & 63653 \\
\hline Fazenda & -402612 & 414879 \\
\hline Indústria e Comércio & -15605 & 17064 \\
\hline Justiça & -348036 & 387589 \\
\hline Marinha & -52755 & 55968 \\
\hline Meio-Ambiente & -52488 & 55876 \\
\hline Minas e Energia & -10534 & 11522 \\
\hline Planejamento & -59773 & 67993 \\
\hline Previdência & -364665 & 384585 \\
\hline Relações Exteriores & -19852 & 23251 \\
\hline Saúde & -510088 & 544918 \\
\hline Trabalho & -90662 & 92533 \\
\hline Transporte & -172466 & 183919 \\
\hline Total & -2986400 & 3221734 \\
\hline
\end{tabular}

Quando considerada a relação de respostas cooperativas e não-cooperativas, pode-se observar a intensidade com que ocorre a diferenciação das respostas das diversas organizações. Diferentemente do comportamento diante da variável quantidade de servidores, a quase totalidade das organizações do governo comportase com a relação $\mathrm{C} / \mathrm{NC}$ menor ou igual a 1 , revelando que elas tendem a apresentar o comportamento não-cooperativo como dominante. Observa-se que os valores de $\mathrm{C} / \mathrm{NC}$ para a maioria das organizações situa-se entre 0,85 e 0,94 .

Quadro 7. Organizações com C/NC entre 0 e 1

\begin{tabular}{ll}
\hline Assuntos Fundiários & 0,474 \\
Relações Exteriores & 0,854 \\
MARE & 0,846 \\
AGU & 0,846 \\
Planejamento & 0,879 \\
Justiça & 0,898 \\
Educação & 0,908 \\
Aeronáutica & 0,910 \\
Indústria e Comércio & 0,914 \\
Minas e Energia & 0,914
\end{tabular}

\begin{tabular}{ll} 
EMFA & 0,917 \\
Ciência e Tecnologia & 0,925 \\
Exército & 0,931 \\
Saúde & 0,936 \\
Transporte & 0,938 \\
Meio-Ambiente & 0,939 \\
Marinha & 0,943 \\
Ex-Territórios & 0,948 \\
Previdência & 0,948 \\
Cultura & 0,960 \\
Fazenda & 0,970 \\
Comunicações & 0,980 \\
Trabalho & 0,980 \\
Esportes & 0,994 \\
Ex-Ministérios & 1,000 \\
\hline
\end{tabular}

Dentre as duas organizações que apresentam respostas cooperativas, estas têm $\mathrm{C} / \mathrm{NC}$ muito próximo de 1 , como mostra o quadro abaixo:

Quadro 8. C/NC maior do que 1

\begin{tabular}{ll}
\hline Presidência da República & 1,008 \\
Agricultura & 1,119 \\
\hline
\end{tabular}


No entanto, quando analisados os dados relativos às frequiências de respostas cooperativas $\mathrm{e}$ não-cooperativas no intervalo de tempo considerado, observa-se que:

a) 18 das 27 organizações apresentam relação FC/NC menor do que 1, indicando que elas apresentam um maior número de vezes em que elevam as despesas de pessoal do que reduzem, indicando uma não-cooperação;

b) existem padrões mais regulares de respostas, como por exemplo: 4 organizações têm índice 0,77 , com 10 respostas cooperativas e 13 respostas não-cooperativas; 10 organizações têm índice 0,92 , indicando 11 respostas cooperativas e 12 não-cooperativas; e 5 organizações tendo 12 respostas cooperativas e 11 não-cooperativas;

c) os dados revelam que as organizações comportam-se de modo incremental, i. e, apresentam respostas cooperativas e não-cooperativas que se alternam no tempo.

Quadro 9. Número de Respostas cooperativas e Não-cooperativas por organização

\begin{tabular}{|c|c|c|c|}
\hline Organização & freqüência C & freqüência NC & FC/FNC \\
\hline Ex-Ministérios & 1 & 2 & 0,50 \\
\hline AGU & 9 & 14 & 0,64 \\
\hline Ciência e Tecnologia & 9 & 14 & 0,64 \\
\hline Assuntos Fundiários & 5 & 7 & 0,71 \\
\hline Cultura & 10 & 13 & 0,77 \\
\hline Marinha & 10 & 13 & 0,77 \\
\hline Minas e Energia & 10 & 13 & 0,77 \\
\hline Trabalho & 10 & 13 & 0,77 \\
\hline Ex-Territórios & 11 & 12 & 0,92 \\
\hline MARE & 11 & 12 & 0,92 \\
\hline Educação & 11 & 12 & 0,92 \\
\hline Esportes & 11 & 12 & 0,92 \\
\hline Fazenda & 11 & 12 & 0,92 \\
\hline Planejamento & 11 & 12 & 0,92 \\
\hline Previdência & 11 & 12 & 0,92 \\
\hline Justiça & 11 & 12 & 0,92 \\
\hline Saúde & 11 & 12 & 0,92 \\
\hline Presidência da República & 11 & 12 & 0,92 \\
\hline Aeronáutica & 12 & 11 & 1,09 \\
\hline Agricultura & 12 & 11 & 1,09 \\
\hline Comunicações & 12 & 11 & 1,09 \\
\hline Indústria e Comércio & 12 & 11 & 1,09 \\
\hline Relações Exteriores & 12 & 11 & 1,09 \\
\hline Exército & 13 & 10 & 1,30 \\
\hline Meio-Ambiente & 13 & 10 & 1,30 \\
\hline EMFA & 13 & 10 & 1,30 \\
\hline Transporte & 14 & 9 & 1,56 \\
\hline
\end{tabular}

\section{ANALISANDO PADRÕES GERAIS DE RESPOSTAS ORGANIZACIONAIS}

No sentido de entender como se comportam aquelas agências que mais cooperam e que mais não-cooperam com o governo em relação às duas variáveis, apresentaremos o padrão das respostas no tempo para as diversas organizações do Execu- tivo Federal brasileiro. A análise das respostas dessas agências permitirá entender como estas exibem padrões, ou ciclos de respostas em relação às políticas de controle e ajuste fiscal do governo. Elas cooperariam o tempo todo com o governo reduzindo as despesas de pessoal e o número de servidores, não cooperariam, ou apresentariam padrões mais incrementais de respostas? Haveria di- 
ferenças nos perfis de respostas entre agências que predominantemente cooperam e as que não-cooperam? E ainda, haveria diferenças de comportamento quando consideradas as duas variáveis fundamentais da reforma? Na análise, a variável de interesse corresponde à variação $\mathrm{D}$ das duas variáveis de interesse. Para selecionar a amostra com agências que mais cooperam e mais não-cooperam com o governo em relação a cada variável, considerou-se a relação $\mathrm{C} / \mathrm{NC}$, tomando três conjuntos específicos de organizações: a) as 5 organizações que mais cooperam; b) as 5 que menos cooperam; e c) 5 organizações com $\mathrm{C} / \mathrm{NC}$ intermediário.

\section{VI.1. PADRÕES DE RESPOSTAS - VARIÁ- VEL QUANTIDADE DE SERVIDORES}

Quando consideradas as agências que mais cooperam na variável quantidade de servidores, os dados mostram que são exatamente: Aeronáu- tica, Agricultura, Exército, Previdência e Saúde. As que mais não-cooperam são: Assuntos Fundiários, Advocacia Geral da União, EMFA, Relações Exteriores e MARE. As cinco agências intermediárias são: Planejamento, Meio Ambiente, Justiça, Educação e Trabalho. Examinarei, portanto, o comportamento temporal da variação da quantidade de servidores para essas organizações.

\section{VI.1.1. AGÊNCIAS QUE MAIS COOPERAM}

A principal evidência gerada pelos dados da curva abaixo é um comportamento regular das respostas no tempo, no qual, além dos valores das respostas serem aproximadamente similares, estas são bastante regulares e incrementais, apresentando pequenas variações em cada intervalo de tempo. Isso revela que mesmo as agências mais cooperativas exibem uma reduzida disponibilidade em se engajar nas políticas de reforma.

Gráfico 6. Respostas individuais de organizações do governo - quantidade de servidores

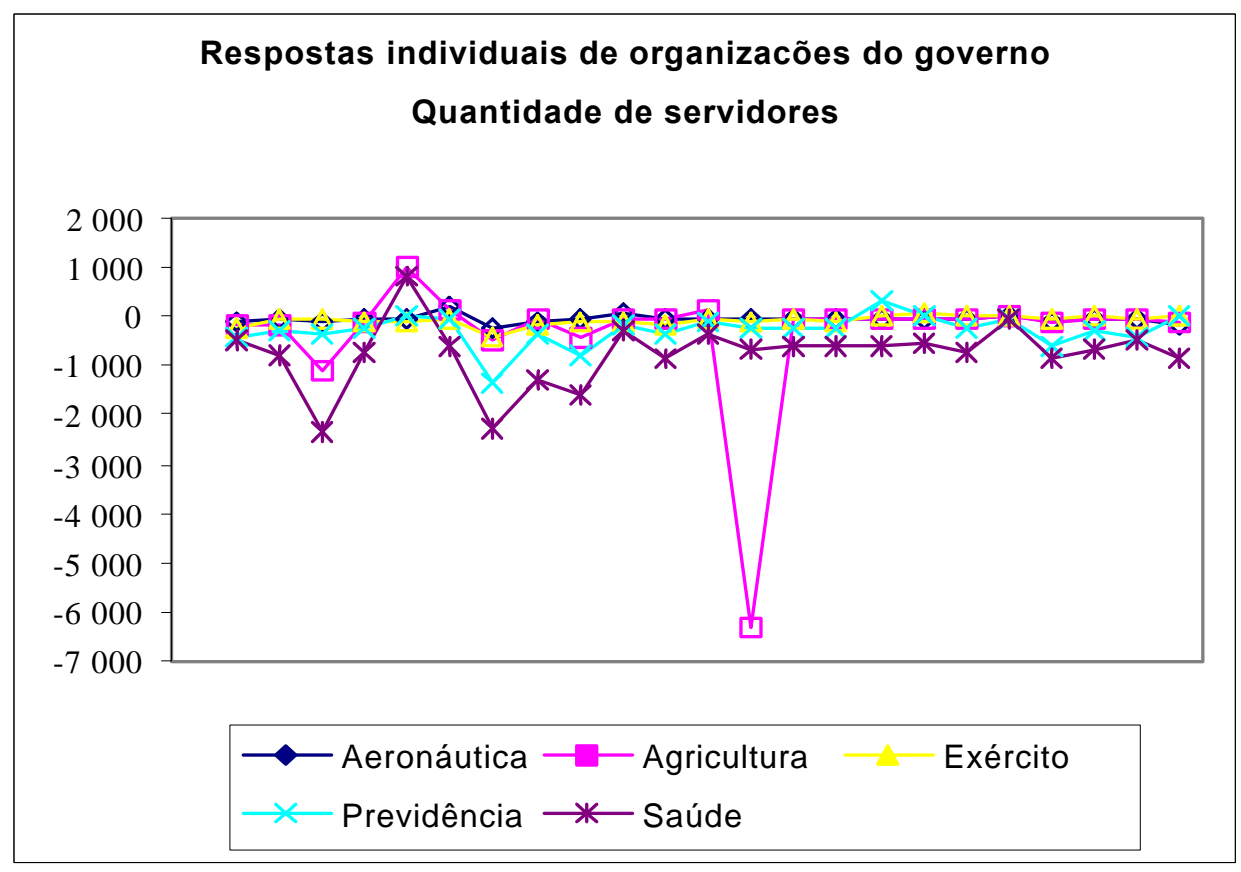

\section{VI.1.2. AGÊNCIAS INTERMEDIÁRIAS}

As agências intermediárias também exibem um padrão regular de respostas no tempo, de natureza muito incremental, sendo todas as organizações consideradas convergentes para um padrão bem definido de respostas. Elas cooperam até um certo ponto, e depois tendem a apresentar estabilidade. Por exemplo, consideremos o caso da Educação, que inicia com uma resposta cooperativa de-6000 servidores, e, cinco intervalos de tempo depois, passa a apresentar uma não-cooperação de 8000 , entrando depois num padrão de resposta muito similar de respostas, situados na faixa [-2 000; 2 000]. Setores como a Justiça, o Planejamento e o Trabalho apresentam comportamentos mais uniformes e bem definidos. 
Gráfico 7. Respostas individuais de organizações do governo - quantidade de servidores

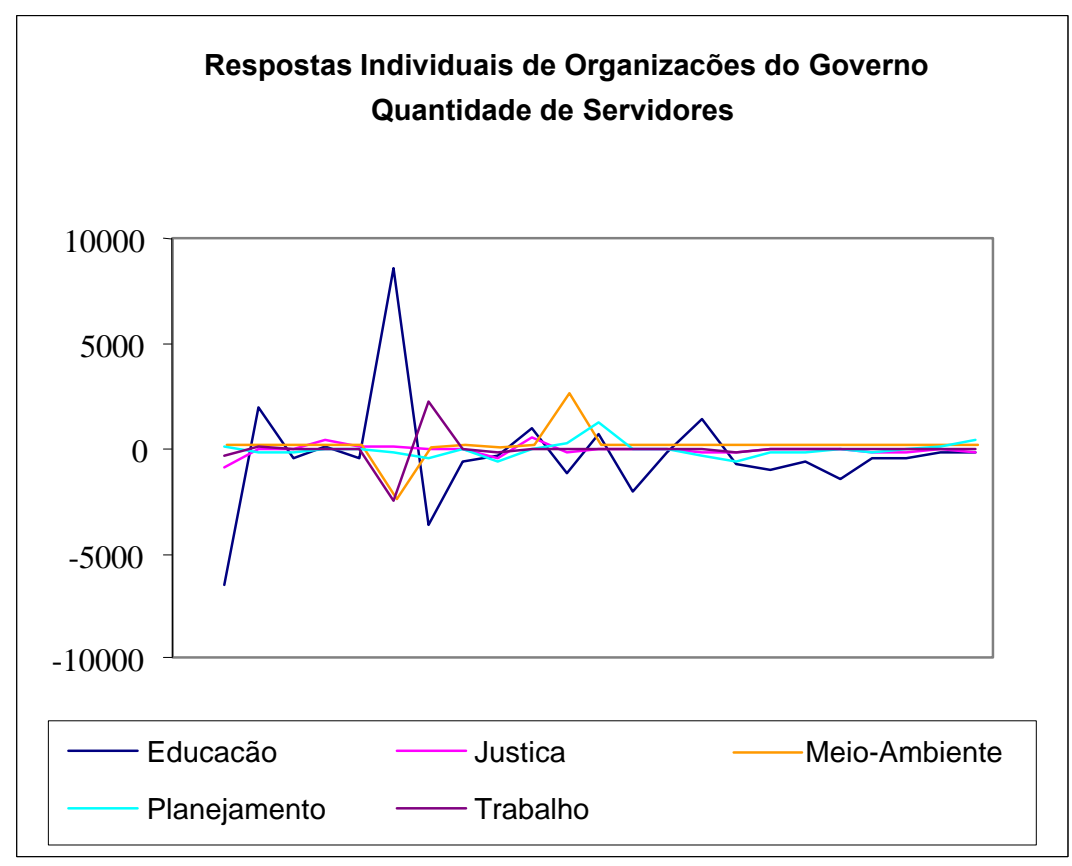

VI.1.3 AGÊNCIAS QUE MENOS COOPERAM demais organizações, qual seja a dominância do

As agências seguem o padrão de respostas das padrão incremental de respostas.

Gráfico 8. Respostas individuais de organizações do governo - quantidade de servidores

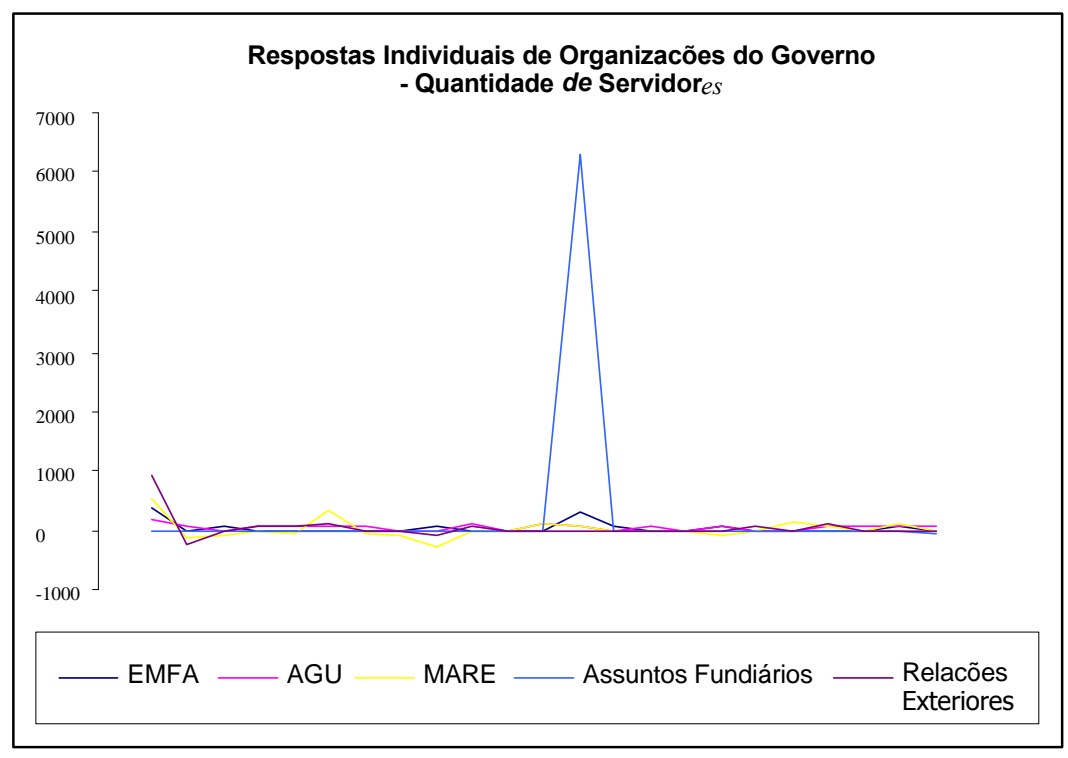

VI.2. PADRÕES DE RESPOSTAS - VARIÁVEL DESPESAS DE PESSOAL

Quando consideradas as cinco organizações do governo que mais cooperam na variável despesas de pessoal, são consideradas: Trabalho, Esportes,
Ex-Ministérios, Presidência da República e Agricultura. As cinco organizações que mais não-cooperam com o governo são: Assuntos Fundiários, Advocacia Geral da União, Planejamento, MARE e Relações Exteriores. As cinco intermediárias 
são: Aeronáutica, Educação, Indústria e Comércio, Justiça, Minas e Energia, e Trabalho.

\section{VI.2.1. AGÊNCIAS QUE MAIS NÃO-CO- OPERAM}

As agências que não-cooperam em relação à variável despesa de pessoal mostram um comportamento também marcado pela regularidade. Dentre as organizações existem variações nas respostas, sendo algumas mais intensas que outras em termos das variações, como o Planejamento, que é o mais intenso de todos, seguido pelas Relações Exteriores. As demais organizações que menos co- operam exibem respostas regulares. Tomando o caso do Planejamento: os dados revelam que esse ministério responde da seguinte forma: ciclos curtos de cooperação e não-cooperação, procurando manter o nível de recursos críticos em um valor necessário para a organização. Vejamos: por exemplo, ela inicia com uma cooperação de aproximadamente -4000 , passando alguns ciclos depois para uma não-cooperação de 15 000, passando no ciclo seguinte para -10000 ; alguns ciclos depois para +10000 , voltando para -10000 , e assim até o final do período. Isso significa cortar e aumentar despesas com pessoal de maneira cíclica.

Gráfico 9. Respostas individuais de organizações do governo - despesas de pessoal

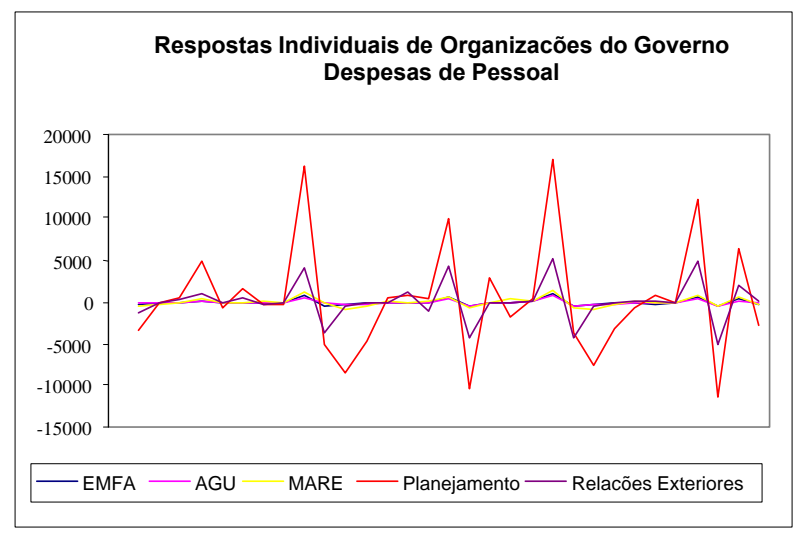

\section{VI.2.2. AGÊNCIAS QUE MAIS COOPERAM}

Esse comportamento cíclico é mais marcantemente acentuado quando se observam aquelas agências que mais cooperam com o governo. No gráfico abaixo, a quase totalidade do conjunto de organizações apresenta esse comportamento, mostrando essencialmente que as agências enga- jam-se na cooperação, mas rapidamente voltam à não-cooperação, de maneira extremamente rápida, revelando o quanto é difícil para o governo fazer que as organizações exibam um comportamento cooperativo mais de longo prazo. Nesse sentido, o engajamento e a mobilização das organizações em torno dos objetivos do governo é pequeno.

\section{Gráfico 10}

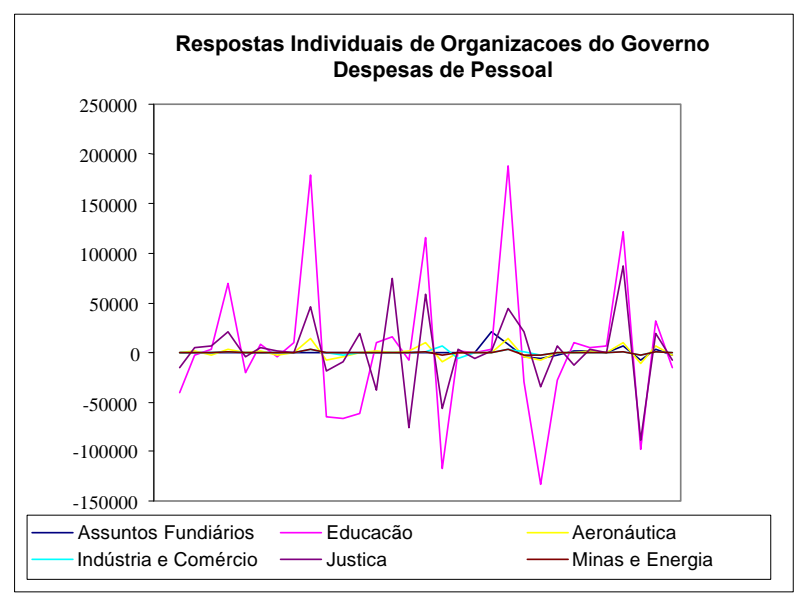




\section{VI.2.3. AGÊNCIAS INTERMEDIÁRIAS}

Neste comportamento também fica evidente o comportamento cíclico e incremental do padrão das respostas às reformas, sendo o setor de Edu- cação o caso mais típico e de maior intensidade. As demais organizações exibem respostas incrementais de pequena intensidade, revelando um padrão dominante de respostas marcadas por pequenas cooperações e não-cooperações.

\section{Gráfico 11}

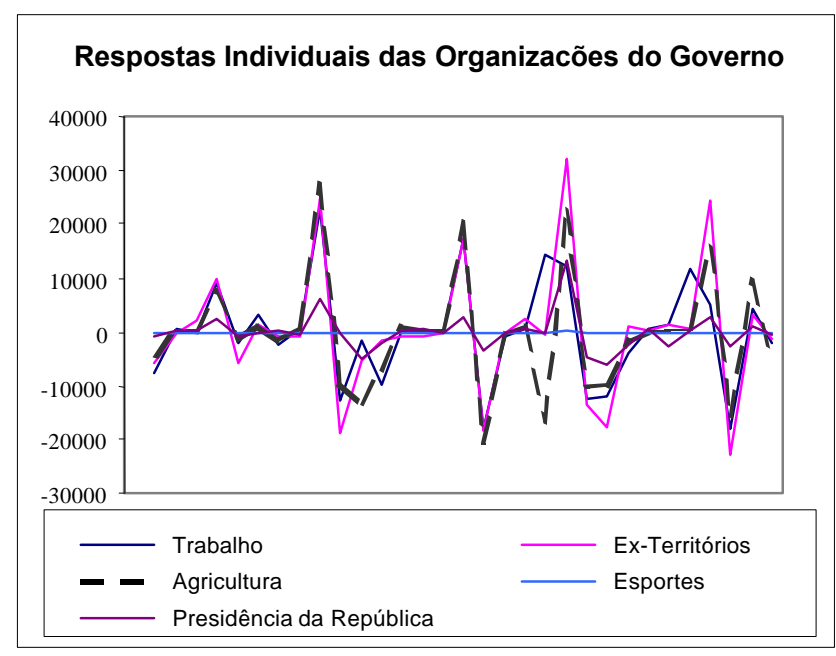

Os dados apresentados para as duas variáveis e para as diversas organizações permitem entender os padrões de respostas da burocracia federal às reformas do Estado, e revelam haver na realidade um padrão típico de respostas que se apresenta similar tanto para a variável despesas de pessoal quanto com a variável quantidade de servidores por organização. Na realidade, as organizações respondem de modo incremental a tais políticas, mantendo um "nível constante" de recursos que garantem a sua existência na estrutura burocrática do governo federal. Elas cooperam, mas apenas por períodos curtos, e logo voltam a não-cooperar, ou vice-versa, revelando uma certa "regularidade" nas respostas. Essa regularidade ilustra o argumento de que as organizações, em realidade, buscam preservar os recursos críticos, e que diante de políticas de controle e redução dos gastos e do número de funcionários, o comportamento agregado das organizações é o de reação às reformas pretendidas pelo governo.

\section{CONCLUSÕES}

Os dados analisados permitem lançar algumas evidências acerca do comportamento burocrático em torno das políticas da reforma do Estado. A primeira delas é que essas políticas geram pequenos incentivos à cooperação das organizações do governo, pela sua própria natureza. Foi empiri- camente evidenciado que as organizações cooperam e voltam a não cooperar, mostrando parecer ser verdadeiro o argumento de que uma organização individual teria poucos incentivos a cooperar, diante de um conjunto de outras organizações que podem estar não cooperando. Isso faz que o comportamento incremental seja mais preferido pelas organizações como escolha racional, levando, num jogo repetido, à preferência pela não-cooperação, de modo que as reformas tendem a atingir resultados muito aquém do esperado. Como explicado anteriormente, como se trata de um jogo repetido de informações incompletas, as organizações procuram ajustar-se muito incrementalmente aos objetivos do governo, pois cada uma delas tem reduzida certeza de que as organizações no seu entorno também se ajustarão, ainda correndo o risco de cooperar demais com tais políticas no longo prazo. Isso explica porque é difícil manter o controle dos gastos com o governo, mesmo diante de políticas de ajuste fiscal e de reforma do Estado. Organizações públicas precisam dos dois recursos fundamentais para sua existência: os funcionários e as despesas de pessoal. Os dados revelam ainda que tal comportamento se mostra verdadeiro para as duas variáveis, indicando que existe um comportamento burocrático mais estratégico diante das reformas do que se poderia supor. Manter as organizações permanentemente engajadas nos propósitos 
das reformas exige tremendo esforço e coordenação, para mobilizar os diversos setores da burocracia, gerando os incentivos necessários e reduzindo o problema de informação incompleta. No entanto, parece ser muito difícil gerar incentivos que auto-alimentem a cooperação em meio ao risco e à incerteza, dado que as organizações apresentam um limite a partir do qual parecem nãocooperar mais. A existência e a dominância do comportamento incremental para as duas variáveis, como mostrado no caso brasileiro, parece confirmar tal hipótese. O comportamento estratégico de respostas incrementais parece ser um comportamento natural e preferido das organizações do governo, e também o mecanismo pelo qual, coletivamente, o governo expande-se. Isso coloca em xeque a idéia niskaneana e as outras explicações sobre o crescimento do governo. A generalização possível seria aquela que mostrasse que o mecanismo pelo qual o governo se expande está relacionado ao fato de as organizações comportarem-se de modo incremental diante dessas políticas. Isso explica, portanto, porque, mesmo diante de políticas de redução com os gastos do governo, o governo e suas organizações continuam, paradoxalmente, a apresentar um comportamento de expansão dos gastos com pessoal e aumentar em tamanho.

Recebido para publicação em 22 de abril de 1999.

Flávio da Cunha Rezende (fcrzen@elogica.com.br) é Ph.D em Planejamento e Políticas Públicas na Cornell University (EUA) e Professor recém-doutor no Mestrado de Ciência Política na Universidade Federal de Pernambuco (UFPE), financiado pelo CNPq.

\section{REFERÊNCIAS BIBLIOGRÁFICAS}

BATOR, F. M. 1958. The anatomy of market failure. The Quarterly Journal of Economics, n. 98 , p. $371-400$.

BRASIL. PRESIDÊNCIA DA REPÚBLICA. 1995. Plano diretor da reforma do aparelho do Estado. Brasília : Presidência da República.

BRESSER PEREIRA, L. C. 1997. A reforma do Estado dos anos 90 : lógica e mecanismos de controle. Cadernos MARE, Brasília, n. 1.

1998a. Uma reforma gerencial da Administração Pública no Brasil. Revista do Serviço Público, Brasília, v. 49, n. 1, p. 5-42, jan.-mar.

. 1998b. Reforma do Estado para a cidadania : a reforma gerencial brasileira na perspectiva internacional. ENAP : Brasília.

BRESSER PEREIRA, L. C. \& SPINK, P. (orgs.). 1998. Reforma do Estado e Administração Pública gerencial. Rio de Janeiro : Fundação Getúlio Vargas.

BRESSER PEREIRA, L. C., MARAVALL, J. M. \& PRZEWORSKI, A. 1993. Economic reforms in new democracies : a social-democratic approach. New York : Cambridge University Press.
GIBBONS, R. 1998. Taking coase seriously. Cambridge : MIT. Mimeo.

HORN, M. 1995. The political economy of Public Administration : institutional choice in the public sector. Cambridge : Cambridge University Press.

IDB. 1997. Latin America after a decade of reforms. Economic and Social Progress in Latin America. Washington D.C. : Johns Hopkins University Press.

LANE, J.-E. 1997. Public sector reform : rationale, trends and problems. California : Sage Publications.

MELO, M. A. B. C. (org). 1999. Reforma do Estado e mudança institucional no Brasil. Recife : Massangana/Fundação Joaquim Nabuco.

MULLER, D. C. 1989. Public Choice II. New York : Cambridge University Press.

NISKANEN, W. 1971. Bureaucracy and representative government. Chicago : AldineAtherton.

OECD. 1987. OECD economic outlook: historical statistics 1960-1985. Paris : OECD. 
1998. Public management reform and economic and social development. Paris : OECD.

OLSON, M. 1965. The logic of collective action. Cambridge : Cambridge University Press.

REZENDE, F. C. 1996. Os leviatãs estão fora de lugar. Dados, Rio de Janeiro, v. 39, n. 2, p. 195-211.

1998a. Clinton e a reinvenção do governo federal : o National Performance Review. Revista do Serviço Público, Brasília, v. 49, n. 1, p. 93-140, jan.-mar. 1998b. How administrative agencies respond to spending control policies : an arena interpretation. New York : Cornell University. Mimeo.

.1999. The Reform of the State as a repeated game of incomplete information. Recife. Mimeo.

STIGLITZ, J. 1998. Redefining the role of the State : what should it do? How should it do it? and how should these decision be made? Speech presented on the Tenth Aniversary of the MITI Research Institute. Tokyo, Japan. March.

\section{OUTRAS FONTES}

MARE. Boletim Estatístico de Pessoal. Vários Volumes. Brasília : MARE.
WORLD BANK. World Development Report. Vários Volumes. Washington D.C. : The World Bank. 